\title{
A SALA DE AULA COMO ESPAÇO DE APRENDIZAGEM: EXPERIÊNCIAS DE ESTÁGIO SUPERVISIONADO
}

\author{
Carlos Cardoso Silva ${ }^{1}$
}

\begin{abstract}
Resumo: Este artigo é um relato de experiência da parceria vivenciada entre os discentes do estágio curricular obrigatório em Pedagogia da Faculdade de Educaçáo da Universidade Federal de Goiás e uma Escola Municipal de Goiânia que trabalha Educação de Jovens e Adultos (EAJA). As experiências estáo voltadas a projetos que tem como referência o conceito de escolas criativa, espaço em que o conhecimento não se restringe a aprendizagem no espaço das salas de aulas. São práticas inovadoras em busca de um ensino de qualidade, crítico e significativo. Tem como princípio a promoção da criatividade e da transdiciplinaridade no recinto escolar. Assim sendo, as relaçóes entre a escola e as práticas criativas e inovadoras não são idealizadas de forma independentes, mas sim como mundos complexos e articulados, criando assim, tensão com dia a dia do educando no mundo da vida e do trabalho, uma vez que são alunos excluídos do ensino regular por demandas desiguais e retornam à escola em idades diferentes formando salas multisseriadas, portanto, com necessidades diferenciadas. De tal modo, estabelecemos um espaço a partir da escola criativa para construir caminhos múltiplos de aprendizagens, de sentidos e significados para os alunos da Educaçáo de Jovens e Adultos (EAJA).
\end{abstract}

Palavras-chave: Estágio. Escola Criativa. Sala de aula. EAJA.

\section{THE CLASSROOM AS A LEARNING SPACE: SUPERVISED MANDATORY INTERSHIP EXPERIENCES}

\begin{abstract}
This essay is the account of experiences that happened through a partnership between the professors of mandatory internship in Pedagogy from the Education College at the Federal University of Goiás and a public school in Goiânia which works with the education of teenagers, young adults and adults (EAJA). These experiences are related to projects that are based on the concept of creative schools, where learning is not limited to the classroom space. They are innovative practices in search of a reflexive, meaningful and better education and their principle is to promote creativity and transdisciplinarity at school. So, these practices consider that the relationships between the school and innovative and creative experiences are not independent, but complex and articulated
\end{abstract}

1 Doutor em Educação pela Universidade Federal de Goiás - UFG. Professor da Faculdade de Educação da Universidade Federal de Goiás - UFG: área: formação de professores (Didática e Estágio Supervisionado).carlos.cardoso27@gmail.com 
worlds. They understand that a tension is created in the student's daily life and it arises from the way this student is excluded from the regular education system and how he later comes back to study at a different age in multiseriate classes with different needs. Therefore, the essay stablishes a space through the creative school to build meaningful and multiple ways of learning for EAJA students.

Keywords: Mandatory Internship. Creative School. Classroom. EAJA.

\section{O Estágio Supervisionado}

O estágio é um período importante e expressivo na formação do futuro profissional de qualquer área do conhecimento, entretanto, é de fundamental importância para o profissional da educação que trabalha diretamente com o formador de todas as outras profissões. A partir desta perspectiva, este texto apresenta, uma reflexão sobre as ações de formação inicial e continuada desenvolvidas no decorrer do estágio supervisionado do Curso de Pedagogia da Faculdade de Educação da Universidade Federal de Goiás - FE/UFG, em anos iniciais do ensino fundamental na educação de jovens e adultos (EAJA), em uma escola campo de estágio da Secretaria Municipal de Educação de Goiânia (SME Goiânia).

O estágio supervisionado é uma experiência fundamental para a formação de futuros educadores, por permitir o contato direto com um dos possíveis espaços de atuação do/a pedagogo/a. No período do estágio as/os estudantes vivenciam a realidade das salas de aula da educação de jovens e adultos, como também, colocam em prática conteúdos subsidiados pelas teorias estudadas durante a formação, tanto no período de observação, quanto na elaboração do planejamento, dos planos de aula e na execução da aula da regência.

No processo de formação as/os estudantes vivenciam e elaboram reflexões na construção de sua identidade profissional. A partir do encontro e confronto entre as teorias e as práticas educativas, o/a estagiária/a vivencia e realiza de forma sistemáticas análises que proporcionam a sua compreensão do espaço escola e educação, e principalmente, da sala de aula. Pimenta e Lima (2009, p. 112) afirmam "à luz das teorias, na elaboração de teorias, o que permite caracterizar o estágio como um espaço de mediação reflexiva entre a universidade, a escola e a sociedade".

Neste processo de mediação entre universidade, escola e a sociedade percebese nos discentes um processo de emancipação diante das questões oriundas de suas vivências escolares e o confronto com a realidade da escola campo possibilitando a construção de sua identidade profissional. Portanto, o estágio é o espaço onde a teoria e a prática se encontram e se contextualizam permitindo ao futuro docente uma concepção e internalização da importância da teoria ser compreendida como norteadora de uma prática e que ambas estão interligadas. Compreendemos o papel do estágio como um campo teórico-prático, pois concordamos com Paulo Freire ao afirmar que "A prática de pensar a prática é a melhor maneira de aprender a pensar certo. O pensamento que ilumina a prática é por ela iluminada tal como a prática que ilumina o pensamento é por ele iluminado" (FREIRE, 1978, 68). A 
sala de aula representa este espaço de pensamento em ação, porque é um local de interação do pensar e do fazer pedagógico.

Na EAJA devido a sua historicidade percebemos ainda bastante presente nas escolas a marca do processo de caráter compensatório e aligeirado, resultado de uma concepção de ensino supletivo. Bem como a visão equivocada de alunos e professores que tendem a priorizar questões relativas ao ensino, muitas vezes pautada em uma perspectiva tradicional, em detrimento do processo de ensino aprendizagem por compreensão. No momento do estágio é possível ter clara esta percepção quando verifica-se que professores, em sua maioria, tende a concentrar mais atenção no conteúdo a ser trabalhado em sala com os alunos a compreender o ritmo e o processo de aprendizagem de cada indivíduo e suas dificuldades, bem como suas potencialidades. Conforme Barreto, J. C. e Barreto, V. (2006, p. 65-66) afirmam sobre os alunos:

Sentem-se frustrados quando a professora fala de coisas do seu dia a dia. Não
vieram para aprender melhor o que está próximo deles. Querem saber sobre
o que está distante. Na sua imaginação, é o conhecimento desse distante que
permitirá a melhoria de sua vida. Outra ideia muito forte que trazem sobre
como aprender melhor é a crença cega no poder de repetição. Baseados em
sua experiência de vida, em que na quase totalidade das vezes aprenderam as
coisas vendo os outros fazerem e tentando fazer depois, acreditam piamente
que irão aprender se repetirem muitas vezes o que estão procurando aprender.

Esta concepção de escola e de ensino-aprendizagem que as/os estagiários/as observam nas/nos educandos, também está muito presente nas/nos educadores, e no processo de formação da/o estagiária/o precisam ser analisados e desconstruídos. Trata-se de um processo de reflexão que leve as/os educandos a compreender que: a escola é um espaço que os auxilia a (re)construir conhecimentos necessários, mas isto não se traduz em uma relação direta com a garantia de uma vida melhor e socialmente mais valorizada, como ideologicamente tem sido apresentado pela sociedade; por outro lado faz-se necessário que a/o educanda/o compreenda que sua condição de vida não é apenas culpa sua e que vivendo em uma sociedade de classes sociais, num sistema capitalista, as relações e o privilégio de pertencer ou não a uma determinada classe interfere nos destinos individuais, cuja condição social não se resume a ter escolarização; à escola compete não apenas ensinar informações distantes e curiosas, mas à apropriação, construção e reconstrução do conhecimento pela/o educanda/o, o que não perpassa apenas pela reprodução, cópia, memorização ou a mera transmissão de informações, sem desafiar e estimular as/os alunas/os no estabelecimento das relações entre os saberes de experiência feitos e os saberes técnico-científicos, historicamente produzidos e sistematizados.

"Esse exercício de pensar, de estabelecer relações não se restringe ao que é dito pelo professor. Pode acontecer e acontece a todo momento, inclusive a partir do que é dito pelos colegas". (BARRETO, J. C. e BARRETO, V., 2006, p. 66). É que no papel de mediador em uma sala de aula, quem exerce esta função, apesar de ser um papel fundamental do/a professor/a e ele/a não se restringe, pois a fala das/os colegas da/o educanda/o, não se configura em perda de tempo, mas sim 
valiosas oportunidades de conhecer, de aprender com o outro que domina outros saberes, pois não é apenas o/a professor/a que sabe na sala de aula.

Outra desconstrução que necessita ser feita é a visão de que o conhecimento não decorre apenas do totalmente desconhecido e socialmente valorizado, mas que aprendemos a partir do que já conhecemos, entrecruzando ao novo saber, reelaborando de um externo para um interno e vice-versa; bem como também nesse processo muitas vezes compete à escola ajudar a/o aluna/o a organizar o conhecimento que possui, ampliando este conhecimento, portanto conhecendo melhor, com maior intensidade e profundidade o que já conhecia, o já sabido. Além é claro que compete também à escola conhecer o que a/o aluna/o já sabe para, nos casos deste saber estar equivocado, auxiliá-la/o na desconstrução e reconstrução deste saber, bem como também são objetivos da atividade escolar aprender novos saberes ainda não dominados.

Contudo, o grande equívoco das/os alunas/os da EAJA (e muitas das vezes também do professor) é conceber que é por meio da repetição mecânica do conhecimento sistematizado que se pode aprender (ou ensinar). Necessitam compreender no processo de aprendizagem dos conhecimentos, quer seja no cotidiano de sua vida, ou escolar, que ao observarem, acessarem informações ou trocarem-nas entre si (via professor, colegas, meios de informação e comunicação, livros, etc.) com o objetivo de aprender, estabelecem relações, comparam com outros saberes, outras formas possíveis de fazer o que estão observando, lendo, vendo etc. e refletem, pensam sobre o que viram, observaram, reelaboram e tentam (re)organizar o seu modo de fazer: pensaram sobre o que tinham visto ser feito e/ou os movimentos a serem feitos, compararam os resultados obtidos com os desejados, criaram novas alternativas, pensaram enfim sobre o que estavam fazendo ou querem ver/fazer e só depois que aprenderam, conseguiram repetir mecanicamente, o que então já sabiam.

Portanto, é um equívoco a ser desconstruído a concepção de que se aprende pela mera repetição, crença com a qual grande parte das/os alunas/os (e de professores/as) da EAJA chegam na escola. E é por meio da reflexão, inclusive de uma outra concepção e tendência pedagógica de escola e de ensino-aprendizagem que podemos construir uma escola significativa, que possibilite uma formação crítica, historicamente situada e possibilite a intervenção na realidade social com vistas à transformá-la. Já que esta concepção tradicional de escola, apenas contribui para perpetuação da sociedade como está.

Ao perceber a importância da reflexão teórica e a ação do/a professor/a em sua atuação no processo de ensino e aprendizagem, a/o futura/o docente visualiza o campo de conhecimento originário de cada aluna/o e compreende que o ato de ensinar não é um processo de reprodução do conhecimento e que a aula não é uma palestra pontual, mas sim, uma ação intencional, planejada, contínua e sustentada por um referencial teórico que fornece uma diretriz para pensar o homem, a sociedade e o processo de ensino, por isso como afirma Freire (1978, p. 168) "A profissão do professor está situada exatamente entre o conhecimento 
sistematizado que a escola oferece e o aluno, portanto, se desenvolve nessa ponte representada na mediação entre o aluno e o saber, o ensino e a aprendizagem". $\mathrm{E}$ o papel do/a professor/a enquanto mediador/a não pode perder de vista os saberes de experiência feitos que os alunos já possuem no processo de apreensão do saber sistematizado historicamente, dando sentido a estes saberes, no processo de construção e reconstrução dos conhecimentos.

Assim, o estágio tem a finalidade de propiciar ao aluno a aproximação à realidade na qual atuará o que requer a adoção de novos procedimentos, uma vez que a efetivação do estágio como uma atividade de conhecimento, requer fundamentação, diálogo e intervenção na realidade, pois é no contexto da sala de aula, da escola, do sistema de ensino e da sociedade que a práxis se efetiva (PIMENTA, 2009). Portanto, o estágio é o momento de apropriação, elaboração teórico-prático dos conteúdos e conhecimentos vistos, vividos e aprendidos durante o curso no processo de formação profissional.

\title{
Nova Perspectiva para o Estágio Supervisionado
}

$\mathrm{Na}$ perspectiva de romper com a visão de estágio no sentido tradicional onde os procedimentos seriam focados no professor transmissor de conhecimentos elaborando, preenchendo formulários e fazendo aulas com repetição mecânica, optamos por uma ação transdisciplinar. De acordo com Suanno (2013. p. 53) a,

\begin{abstract}
transdisciplinaridade caracteriza-se por ser uma pulsão religadora, por buscar pensar complexo, multidimensional, multirreferencial, articulando razão, emoção, corporeidade e atitude transformadora, trabalhando assim com uma razão sensível e uma práxis complexa e transdisciplinar.
\end{abstract}

A partir da transdisciplinaridade a relação com a construção do conhecimento não exclui a elaboração e preenchimento de formulários e relatos escritos, porém ressignifica-os a partir da realidade de cada aluno/a no processo de ensino e aprendizagem tendo como eixo central o diálogo. Neste processo de dialogicidade ocorre uma interação de saberes que permite cada educando/a sentir-se como parte do grupo e seu saber é valorizado e sistematizado a partir da sua compreensão de mundo e de suas vivencias e experiências

No sentido de romper com a educação tradicional que retira o diálogo, uma vez que o detentor do saber é o professor e o aluno fica na condição de tábua rasa, ou recipiente a ser preenchido por um saber elaborado pela cultura, geralmente, da cultura dominante. Tentando romper com esta visão homogênea de educação é que o projeto de escolas criativas procura apresentar uma nova alternativa de ver e pensar o ato educativo, a relação de ensino e aprendizagem, a relação professor/ aluno numa perspectiva multidisciplinar, transdisciplinar e complexa, surge a opção da escola criativa.

Romper com a visão autossuficiente da escola tradicional exige uma nova perspectiva de mundo, de ser humano e de viver, pois significa insurgir contra a autossuficiência, como afirma Freire (2011, p. 112): 
A autossuficiência é incompatível com o diálogo. Os homens que não têm humildade ou a perdem não podem aproximar-se do povo. Não podem ser seus companheiros de pronúncia do mundo. Se alguém não é capaz de sentir-se e saber-se tão homem quanto os outros, é que lhe falta ainda muito que caminhar, para chegar ao lugar de encontro com eles. Neste lugar de encontro, não há ignorantes absolutos, nem sábios absolutos: há homens que, em comunhão, buscam saber mais.

O conceito de Escolas Criativas, também apresenta o rompimento com a autossuficiência, pois ensinar é um processo político e ao se saber político há uma preocupação com o outro, com a autonomia, com o diálogo. Para De La Torre e Violant (2003, p. 1):

La creatividad, al igual que la comunicación, son un conceptos polisémicos, cargados de múltiples connotaciones educativas, sociales, psicológicas, filosóficas, artísticas, científicas... Ambos se adentran en el ser humano, se originan en la necesidad o problema, se desarrollan en la interacción de la persona con el entorno, y se consuman en la participación y proyección hacia los demás.

Esta aproximação de Freire e De La Torre nos apresenta condições de elaboração de uma nova leitura do ser do humano. Na afirmativa Freiriana: "Neste lugar de encontro, não há ignorantes absolutos, nem sábios absolutos: há homens que, em comunhão, buscam saber mais" (2011, p. 112) e na afirmativa de De La Torre; ", se desarrollan en la interacción de la persona con el entorno, y se consuman en la participación y proyección hacia los demás" (2003, p. 1), está posto a possibilidade dialógica e do encontro entre os seres, portanto, a dimensão de humanidade se faz presente neste processo dicotômico instaurado pela razão cartesiana com a separação entre: Sujeito - Objeto; Alma - Corpo; Razão Sentimento; Liberdade - Determinismo e Finalidade - Causalidade proposto e imposto pela visão tradicional de educação. Este texto intenciona aproximar a escola criativa com o Estágio Supervisionado como espaço de humanização e diálogo.

Diante do exposto surge a necessidade de especificar o que é ou que são escola/s criativa/s. Saturnino De La Torre aponta as diretrizes para construção desse modelo de escola a partir de seus estudos sobre a criatividade humana. Importante ressaltar que quando se refere a criatividade há uma tendência generalista de colocála em nível do senso comum esquecendo ou de forma pejorativa e degradante apontá-la como menor.

No desenvolvimento de ensino na perspectiva da escola criativa é necessário uma Didática que apreenda a dimensão da criatividade deixando de ser um recurso instrumental com finalidade apenas de saber fazer. A partir desta perspectiva, questionamos: por que o estágio numa perspectiva criativa? O estágio supervisionado é uma disciplina de caráter teórico-prático exige do professor um método, uma metodologia e um referencial para o aprofundamento teórico e fundamentar a prática docente com o objetivo de proporcionar ao futuro docente uma formação de qualidade. 
O estágio como a didática são áreas que tem como especificidade o estudo da prática pedagógica, se ocupa do processo ensino-aprendizagem e das técnicas de ensino, bem como da formação de professores. Portanto, é um o estudo que exigem fundamentos teóricos e criatividade. São fenômenos intencionados por uma consciência. Compreendendo e interpretando o sentido e o significado do fenômeno, o mundo fenomenológico se evidencia, aparece (BICUDO, 1999). O mundo da criatividade, assim como o mundo fenomenológico, se dá por meio da consciência que intenciona e visa algo. Em específico, a escola criativa visa um novo significado ao ato de ensinar e aprender por meio de um processo de humanização do sujeito ensinante e aprendente é nesta perspectiva que visamos a prática de estágio supervisionado.

Com ênfase na fenomenologia e na criatividade procuro discutir e a apresentar a o estágio supervisionado como um conhecimento direcionada para o humano e que tem como finalidade a educação e a formação do ser humano. A partir desta compreensão, a o estágio volta a sua ação para o homem em seu processo de pensar, de refletir sobre a aquisição de conhecimentos, do ensino e da aprendizagem para elaborar e transmitir aos educandos. Como a reflexão sobre o ato de conhecer, esta ação visa aos atos e aos correlatos da consciência no processo de ensino/aprendizagem. O estágio visa a formação do/da discente a compreender o processo de aprendizagem do que é ser professor/a, da relação de ensino e aprendizagem, do espaço da sala de aula e da ação pedagógica.

Desta forma, ao pensar o Estágio Supervisionado como prática didática, considero importante destacar a preocupação de Husserl com o ser humano, sua humanidade e o mundo em que ocorrem as experiências humanas (HUSSERL, 2002). Para ele é fundamental compreender como o homem vivencia as experiências, pois não há possibilidade de conceber um sujeito sem mundo, da mesma maneira que não é possível um mundo sem sujeitos. Neste aspecto, a criatividade é resultante desse exercício humano de ser e pertencer ao mundo.

A criatividade não é um dom divino e sagrado recebido de um oráculo, mas sim um aprendizado que exige rigor, método e disciplina para sua aquisição e desenvolvimento. Como assinala Violant e De la Torre (2003), a criatividade como a comunicação se originam da necessidade ou de problema surgidos ao sujeito e se desenvolvem na interação da pessoa como o meio a qual está inserida e eles são ampliados na participação e divulgação para outros sujeitos. Deste modo, ser criativo exige estudo, método, disciplina e fundamentalmente, a valorização do ser humano que produz e partilha conhecimento. Novamente, aproximando de Paulo Freire, na obra Pedagogia do Oprimido (2011, p. 68) "ninguém educa ninguém, ninguém educa a si mesmo, os homens se educam entre si, mediatizados pelo mundo".

Logo, se ninguém educa sozinho, o ato criativo também não se faz sozinho. Tanto o ato educativo como a criatividade são produtos de construção históricosocial das ações humanas mediatizadas pelo mundo-vida dos sujeitos humanos. Por isso, na escola criativa a ação de educar, de aprender, de ensinar são produções 
históricas dos homens participantes e que ocorrem de forma coletiva, dialógica e humanizadora. A perspectiva dialógica se faz no movimento do existir, do viver, de construção da História e da Cultura que é presente no mundo humano, isto é, a prática educativa ocorre e se concretiza entre os seres, no convívio social, familiar, profissional, escolar, ou seja, na vida. A educação não é propriedade da escola, não é um processo de adequação a um mercado, a serviço de produção de consumo, como a aula não é produto e posse do/a professor/a.

A educação tem um sentido antropológico, é um processo de apropriação que o sujeito faz da natureza humana, o qual é construído e constituído pelo próprio ser humano. Neste aspecto, o ato educativo é filosófico, como Consciência de alguma coisa, consciência que visa algo, a educação é um projeto humano visado e permeado pela reflexão em busca de uma práxis. Severino (1990, p. 19) “considera que na história da cultura ocidental a educação e a filosofia sempre estiveram juntas e próximas e se formaram unidas a uma intenção pedagógica".

Nesta perspectiva, a compreensão da relação do sujeito com o mundo é fundamental para a aquisição do conhecimento. O homem como sujeito é que dá sentido e significado a existência, no entanto, com o desenvolvimento da ciência na idade moderna a humanidade é esquecida e o campo científico busca responder todas as questões do espírito humano. Para Severino (1990, p. 19 - 20) a cultura contemporânea:

Fruto dessa longa trajetória do espírito humano em busca de algum esclarecimento sobre o sentido do mundo, é particularmente sensível a sua significativa conquista que é a forma científica do conhecimento. Coroamento do projeto iluminista da modernidade, a ciência dominou todos os setores da existência humana nos dias atuais impondo-se não só pela sua fecundidade explicativa enquanto teoria, como também pela sua operacionalidade técnica, possibilitando aos homens o domínio e a manipulação do próprio mundo. Assim, também no âmbito da educação, seu impacto foi profundo.

Com a influência da operacionalidade técnica no processo educacional como ocorreu nas diversas áreas do conhecimento humano, a educação também passa a ser visada e desenvolvida na dimensão científica com objetivos de resultados e explicações fundamentadas pela visão da ciência positivista. Severino (1990, p. 20) explica que "como qualquer outro setor da fenomenalidade humana, também a educação pode ser reequacionada pelas ciências, particularmente pelas ciências humanas que, graças a seus recursos metodológicos, possibilitam uma nova aproximação do fenômeno educacional"

Assim como a educação foi direcionada para a concepção científica, o estágio e a didática também passaram serem vistos instrumentos técnicos de melhoria do processo de ensino-aprendizagem. No Brasil, no século XX, com a acentuada ascensão da educação tecnicista, principalmente na ditadura militar, oriundos dos acordos MEC-USAID firmados na década de 1960. Acordos entre o Ministério da Educação brasileiro (MEC) e a United States Agency for International Development (USAID) que visavam estabelecer convênios de assistência técnica e cooperação financeira à educação brasileira. Os conteúdos do estágio tinham como finalidade 
os métodos e técnicas de ensinar a ensinar, bem como apresentar informações aos educandos de maneira desvinculada sobre a intenção do processo de ensino, ou seja, sem considerar a experiência de vida do aluno e do professor no ato educativo, ou seja, buscava o ensino técnico e mecânico.

Neste aspecto, retirava dos docentes e discentes a condição de sujeitos do conhecimento, onde o conhecimento é a busca constante do ser humano interagir e se integrar no mundo. Da relação sujeito-mundo o homem estabelece o seu agir, as finalidades da sua ação como ser de consciência e institui os valores do seu grupo e da sua sociedade, é um processo histórico que "constitui uma tentativa de intencionalização do existir social no tempo histórico" (SEVERINO, 1990, p. 21). Por isso, a educação escolar, no exercício de sua função social de educar, de preparar para a vida deve estar atenta, para a prática pedagógica, para as dimensões do ato educativo que permeiam o processo de formação dos educandos enquanto sujeitos que pertencem ao mundo no sentido mais concreto da existência humana.

Neste contexto, é necessária uma prática didática que rompa com os paradigmas de instrumentalização e de tecnicismo do estágio ainda presente na prática pedagógica atual, "como a prática como imitação de modelos" e "a prática como instrumentalização técnica" (PIMENTA, 2009). Neste aspecto, a concepção instrumental tem como objetivo a construção de um modelo de planejamento de curso, elaborados por módulos de ensino, com características básicas de um planejamento didático a partir da abordagem sistêmica; na compreensão da didática tecnicista, onde o fundamental era o estudo dos métodos e técnicas que enfocavam uma perspectiva de neutralidade. Em ambas as vertentes, a preocupação era com um conhecimento elaborado, sistematizado e normativo que deveria ser repassado. Contrariando essas visões, Pimenta e Anastasiou (2002, p. 67) afirmam que a didática:

Investiga os fundamentos, as condições e os modos de realizar a educação mediante o ensino, sendo uma ação historicamente situada, a Didática vai constituindo-se como teoria do ensino. Não para criar regras e métodos válidos para qualquer tempo e lugar, mas para ampliar nossa compreensão das demandas que a atividade de ensinar produz.

Assim como, a didática volta a sua ação para o homem em seu processo de pensar, de refletir e na aquisição de conhecimentos; trabalha com os elementos da didática (planejamento, objetivos, estratégias, metodologias e avaliação) de maneira contextualizada e articulada, em consideração com a dimensão humana, sociocultural e técnica da prática pedagógica; o estágio supervisionado, também, não concebe o ato educativo neutro, não há neutralidade quando há opções e visões de mundo envolvidas em situações determinadas; neste aspecto os valores e as opções que orientam a escolha de métodos, conteúdos e formas de avaliação na formação do professor/a. Esta ação é uma articulação da teoria e da prática que ocorre por meio de uma interação constante na realidade da prática escolar em busca de novas formas de conhecimentos e novas formas de abordagem do ensino/aprendizagem e da formação humana. 
O projeto de Escola Criativa visa romper o dualismo resultante da separação teoria e prática que propicia o distanciamento entre ambas, ocorrendo então, a visão simplista de que na teoria há uma proposta a realizar, porém na prática não possível a realização da proposição teórica. Rays (1996, p. 36) esclarece que a evolução da teoria é correspondente à evolução da prática que ocorre sempre ligada à evolução da teoria, pois:

Esse princípio de identidade faz com que teoria e prática sejam dinâmicas. Às vezes pensamos, equivocadamente, que a teoria é sempre a mesma, que a prática é sempre a mesma e que ambas desenvolvem-se autonomamente. Mas, se pensarmos mais detidamente vamos concluir que, a um só tempo, teoria e prática movem-se e transforma-se continuamente. Em nenhum momento da atividade humana a teoria e a prática estão imóveis, uma vez que a teoria não exclui a prática e a prática não exclui a teoria na atividade social dos homens.

Portanto, teoria e prática são partes integrantes de um todo, isto é, não atuam separadas, são partes que constituem de forma dinâmica no processo histórico da atividade humana na sociedade. "A onilateralidade da teoria e da prática é que propicia ao homem conhecer corretamente a essência do mundo da cultura e do mundo da natureza" (RAYS, 1996, p. 37), e consequentemente, o conhecimento do mundo vida humano. Diante desse processo de conhecimento, o campo didático-pedagógico deve conter a relação teoria-prática as características de um ato científico contextualizado, evitando a fragmentação do processo de ensinoaprendizagem com relações mecânicas, técnicas e arbitrarias no processo de apreensão da realidade; uma vez que o ato de conhecer e assimilar um conteúdo ou objeto é um fenômeno que o humano realiza numa ação prática. Conforme Rays (1996, p. 37):

O conhecer é, portanto, ação que não exclui a teoria da prática e a prática da teoria, ao tratar de problemas concretos em suas relações históricas. É assim que ao ato de conhecer, entendido como ação, como atividade humana consciente, transforma-se na verdadeira força motriz da evolução sociocultural e da determinação de seu desenvolvimento futuro.

Deste modo, o processo didático pedagógico da aula é uma construção permanente entre a teoria e a prática. A aula é um processo de ensino e aprendizagem em que deve ser significativa e com participação dos educandos. Por isso, é necessário romper com o processo de transmissão de conhecimentos e conteúdos centrados no professor e nos matérias didáticos. É de fundamental importância na educação da EJA que as vivências e as experiências dos alunos/as sejam inseridas no procedimento das aulas. São vivências do mundo-vida de cada pessoa que não sabe ler e escrever, porém tem experiências pessoais significativas, por isso, é importante as aulas partir das suas necessidades emergentes para um desenvolvimento maior de habilidades e aprendizagens. 


\section{A Sala de Aula}

Diante das questões teóricas discutidas em sala de aula com os estagiários/ as e das observações feitas em salas de aulas na escola campo foram elaboradas as propostas das regências a partir da realidade dos alunos/as da EAJA. A escola campo, onde realizou-se o estágio supervisionado, tem três salas de aulas de EAJA atendendo alunos de 18 a 86 anos de idade, dividas do primeiro ao quarto ano ou de $1^{\mathrm{a}}$ a $4^{\mathrm{a}}$ séries; sendo $1^{\mathrm{a}}$ e $2^{\mathrm{a}}$ séries individuais e a $3^{\mathrm{a}}$ e $4^{\mathrm{a}}$ séries unificadas.

$\mathrm{Na} 1^{\mathrm{a}}$ série, após a diagnose realizada com os educando/as, o interesse da turma foi para estudar o meio ambiente. Diante da demanda apresentada elaborou-se o projeto de ensino/aprendizagem intitulado: "Preservando o Meio Ambiente". O motivo da proposta em primeira instância é possibilitar a ampliação de vocabulário no processo de alfabetização e letramento e conhecimentos sobre o meio ambiente.

A partir de conteúdos da educação ambiental na EAJA e das dificuldades que os alunos apresentaram em leitura e escrita o projeto teve por intuito desenvolver em sala de aula, por meio de sequências didáticas, variados temas sobre o Meio Ambiente, como: vídeos, músicas, poemas, obras literárias, reportagens impressas, dinâmicas e reflexões. Foram abordados temas sugeridos pelos alunos/as como Água, Solo, Fauna, Flora, Biosfera, Ética e Cidadania e o papel do homem no Meio Ambiente.

A partir do interesse apresentado pela turma, desenvolveu o projeto de ensino de forma transdisciplinar o que possibilitou novos conhecimentos no processo de alfabetização e letramento a partir da realidade e de conhecimentos prévios dos alunos/as.

$\mathrm{Na} 2^{a}$ série, havia consenso dos participantes que gostariam de comunicar melhor por meio da escrita, sem erros e com maior fluência. Foi proposto a partir da demanda dos estudantes o projeto "A leitura e escrita a partir dos gêneros textuais", com ênfase em atividades de leitura e escrita. Como disse um aluno: "queremos ser praticantes da leitura e da escrita".

As atividades focaram nos gêneros carta, convite, bilhete e pequenos cartazes. Esta turma era formada, na maioria, de trabalhadores autônomos que residem no próprio bairro ou trabalham nas proximidades da escola, com faixa etária de 20 a 68 anos. A maioria veio do interior de Goiás e das Regiões Norte e Nordeste, demonstram grande interesse no processo de alfabetização para melhorarem sua situação econômica e pessoal.

As atividades promoveram o resgate da autoconfiança dos alunos, dando-lhes segurança para reconhecer alguns gêneros textuais, possibilitam-lhes desenvolver a leitura e a escrita, melhorar a comunicação oral e a redação de pequenos textos.

As aulas foram realizadas articulando conteúdos multidisciplinar focados na leitura, na escrita e na comunicação oral. Utilizando de atividades transdisciplinar vivenciou situações diversas de comunicação, onde os alunos expressaram oralmente e escreveram as situações em que eles se envolviam no dia a dia. Por 
meio de representações e de personagens diversos foram apresentadas situações do cotidiano. A partir das atividades houve uma participação ativa do grupo e de aprendizagem significativa, conforme relataram nas avaliações relatadas em sala.

$\mathrm{Na}$ turma de $3^{\mathrm{a}}$ e $4^{\mathrm{a}}$ séries unificadas, o interesse foi para educação para o transito. A turma manifestou um grande interesse em conhecer as leis de transito, pois a maioria dos alunos/as, queriam ter habilitação para dirigir. A composição da turma era na maioria de estudantes homens e mais jovens, as idades variavam de 23 a 58 anos; mesmos as alunas também havia interesse em dirigir, também eram mulheres jovens, na mesma faixa etária citada.

A partir do Código de Transito Brasileiro (CTBO, 1997) foi desenvolvido o "Projeto Escola, Trânsito e Cidadania" com o intuito de discutir com os alunos a importância da segurança no trânsito; identificar regras de circulação no transito; identificar o significado da sinalização; a importância à obediência ao semáforo, identificação das cores e a sua utilidade; o uso do celular ao dirigir; como congestionamento nas grandes avenidas e ruas da cidade afeta o humor das pessoas. Como o pedestre torna-se uma pessoa vulnerável no trânsito; mal uso do celular ao dirigir e ao atravessar a rua, distraídos, conversando ou ouvindo música, vendo vídeos e usando WhatsApp deixando de focar no que realmente interessa que é a segurança.

$\mathrm{Na}$ realização das aulas os alunos/as estudaram o manual de trânsito de autoescola. Várias atividades foram elaboradas como situações com fantoches, representação de ocorrências vividas pelos estudantes, confecção de placas e sinais de trânsito. O projeto teve como finalidade desenvolver um trabalho didáticopedagógico com os alunos/as da Educação de Jovens e Adultos em um processo de alfabetização, leitura e escrita a partir de uma proposta de educação para o trânsito de forma transdisciplinar.

No encerramento da regência na escola campo reunimos as turmas $\left(1^{\mathrm{a}}, 2^{\mathrm{a}} 3^{\mathrm{a}}\right.$ e $4^{a}$ séries) no pátio as escola para uma atividade coletiva. Esta atividades denomina de "Feirinha Cultural", onde os alunos apresentaram as atividades realizada em sala e expuseram suas atividades de trabalho no cotidiano. Havia bancas de salgados, bolos, doces, churrasquinhos, perfumes, bordados, crochês, manicure, massagens, músicas. Todas a exposição permeados com desenhos, escritas e anotações dos/as aluno/as realizadas em sala durante o período do estágio.

Neste espaço foi observado a aplicação de conhecimentos de matemática, linguagens oral e escritas, socialização entre os alunos/as, os/as professores/as, comunidade e de relações humanas permeadas de alegria, satisfação e realização dos discentes. Naquele momento, não havia adultos, mas sim, a criança de cada um deles estava presente com toda intensidade.

Para Mancuso e Moraes (2009) as feiras culturais são possibilidades de promover uma integração entre aluno e professor, bem como a escola, a comunidade e foi o observado naquele dia de encerramento do estágio na escola campo. Os/as estagiários/as vivenciaram uma aula coletiva fora do espaço sala de aula de forma transdisciplinar aplicando os conteúdos das vivências e experiências 
dos seres humanos envolvidos nos projetos elaborados e executados durante o período do estágio supervisionado.

\section{Consideraçóes Finais}

De acordo com Plano Curricular Nacional (1997), a educação escolar deve ser concebida como uma prática que tem a possibilidade de criar condições para que todos os alunos desenvolvam suas capacidades e aprendam os conteúdos necessários para construir instrumentos de compreensão da realidade e de participação em relações sociais, políticas e culturais diversificadas e cada vez mais amplas, condições estas fundamentais para o exercício da cidadania na construção de uma sociedade democrática e não excludente.

Ação pedagógica na Escola Criativa eu associo a Didática Fenomenológica (SILVA, 2009) uma vez que parte da compreensão das relações do homem no mundo; define-se como um processo de reflexão sobre a prática docente e considera todos os aspectos que fazem parte e integram a vida do ser humano. Por isso, abrange várias dimensões: humana, político-social, técnica, estética, de conhecimento, do lúdico, axiológica, didático-pedagógica, familiar, metodológica e avaliativa.

A dimensão humana caracteriza-se pela compreensão dos valores éticos, dos valores do mundo da vida, das crenças políticas, religiosas, do afeto, da emoção e da razão. Essa dimensão apresenta a noção de inacabamento do ser humano, essa determinação do homem ser concebido como "inacabado" o coloca num processo contínuo e dinâmico de construção do mundo e de si mesmo.

No enfoque didático, no estágio supervisionado é fundamental que o docente perceba o educando como ser em processo de ampliação intelectual e vê-lo como um ser social e integrado ao mundo ao qual pertence e ao seu desenvolvimento cognitivo, afetivo, social e motor, ou seja, que o educador contribua para a formação do aluno como pessoa completa. "O inacabamento do ser ou sua inconclusão é próprio da existência vital” (FREIRE, 2004, p. 50). Este processo perpassa a vida humana individual e coletiva.

No âmbito político-social a escola possibilita aos alunos espaço para o exercício da participação em sociedade, para proporcionar espaços de deliberação de normas e regras em grupos, condições de decisão para que se percebam como sujeitos históricos e com capacidade de assumir compromissos e responsabilidade social que serão necessários para a vida em sociedade e para o exercício da cidadania, portanto, é uma ação de educação para a formação do cidadão, esta relação pode ser mediada pela ação didática entre professores e alunos proporcionando situações de aprendizagem do coletivo e da diversidade humana para conhecer as realidades sociais, as realidades política e econômica que são situações concretas da vida dos educandos.

Portanto, na escola as práticas pedagógicas das diversas áreas de conhecimento devem valorizar e proporcionar condições de discussão e vivência de atitudes 
éticas, de valores de solidariedade, de respeito mútuo, de tolerância e compreensão da diversidade cultural, social, política, religiosa, sexual, física e racial, ou seja, das diversidades humanas que colaborem com a formação de sujeitos éticos.

Para empreender uma educação humanizadora, crítica, rigorosa e reflexiva o elemento primordial é a compreensão da ação pedagógica que tem um papel comprometido com o ser humano em todas as suas diversidades e que a sua metodologia de ensino contemple uma proposta de educação com a sociedade e a humanidade. Seria a educação para a cidadania, cidadania no sentido ampliado, isto é, educar o homem para a vida, para viver em sociedade; para perceber a sua existência e a dos outros homens como um ser político-social, dotado de subjetividade e para que seja eficaz, não deve ser individual e nem individualista. Candau (1995, p.14) esclarece "educar para a cidadania é educar para uma democracia que de provas de sua credibilidade de intervenção na questão social e cultural".

Educar é compreender o homem como ser que dá sentido ao mundo e a existência, conforme Von Zuben (1979, p. 193 - 194) é compreender como o sentido do fenômeno 'educação' se articula com o sentido da emergência do sujeito compromissado historicamente no mundo com o outro. É através da articulação do sentido dos conceitos em questão: o significado da educação e da existência como fenômenos humanos. [...] simultaneamente, o homem é linguagem transformadora (a palavra aqui é atitude, ação). É seu poder de significar, de descobrir sentidos e revelá-los a si e aos outros que o compromete com a realidade. O homem é ação transformadora compromissada com o mundo (cultura) e com os outros (história), a 'emergência do sujeito', ou seu existir como 'advento' por-vir, implica, em seu seio, uma dupla exigência que denota duas dimensões da linguagem: a linguagem como questionamento radical e a palavra como diálogo atuante na transformação do mundo com o outro.

Portanto, é uma ação educativa voltada para o diálogo e a existência em que a articulação homem-mundo revela os seus sentidos, como também não existe homem sem mundo e este não existe e recebe seu sentido senão por meio do homem. "O sentido não reside nem no homem, nem no mundo, mas surge graças à relação que se estabelece entre os dois" (VON ZUBEN, 1979, p. 207); uma das preocupações basilares da fenomenologia é explicitar as relações vividas pelo homem no mundo. Ela se origina de um dado essencial que o homem é um ser-no-mundo, portanto uma prática didático-pedagógica fenomenológica preocupa-se com o sentido e a presença do homem no mundo e atinja o seu sentido nesta presença; a prática pedagógica fundamentada na fenomenologia tem como objetivo possibilitar ao educando perceber o seu sentido, o seu significado, isto é, compreender o seu sentido e a sua presença no mundo humano, da cultura, da história e da existência.

Nesse sentido, a educação é direcionada, especificamente, para a formação de cidadãos, com capacidade de produzir e contribuir para uma nova ordem por meio da ampliação e utilização de técnicas e métodos específicos para cada área do conhecimento humano. 
Em meio ao contexto apresentado, a educação, a didática e o estágio supervisionando estão inseridos numa relação direta com as ciências naturais, o que caracteriza a adoção do método científico vigente. No entanto, como ação científica e pedagógica, a educação escolar, ao trabalhar e tratar com fenômenos complexos como o ensino-aprendizagem, atitudes, comportamentos e relações humanas, deve ultrapassar o modelo clássico de ciência. Não significa abandonálo, mas ir além dele e considerar que o ser humano apresenta características e particularidades específicas de subjetividade que ultrapassam dos fatos físicos observáveis, quantificáveis e controláveis por ações ou instrumentos e técnicas objetivas.

Freire chama a atenção para a importância do ato de ensinar. Numa compreensão do humano situado em condições próprias do seu mundo vida, ele ressalta que o ato de ensinar é uma especificidade do humano, portanto não pode ser separado da existência do ser, do mundo da cultura em que está inserido. Entretanto, é necessário ampliar esse mundo e dotar os sujeitos das condições necessárias para uma vida digna e uma aprendizagem de significados.

O fenômeno educativo é complexo e apresenta várias dimensões que contribuem para o desenvolvimento do processo de ensino e aprendizagem. Uma dessas dimensões é a relação professor-aluno, fundamental para a expressão de um ensino qualitativo. Essa relação se constrói pela ação, pela palavra, pelo silêncio e por mediações diversas do confronto humano de estar e existir no mundo, de se fazer presente nesse processo de humanidade que permeia a prática educativa em sala de aula. Em situação de ensino e aprendizagem essa intencionalidade deve ser presença constante. Portanto, a "afinidade" entre o professor e o aluno é fundamental para o desenvolvimento de uma aprendizagem significativa. No estágio esta ação é constante e preenchida por subjetividades.

A relação pedagógica não se faz de imediato, ela se faz de tessituras, de silêncios subjetivos e objetivos, da relação intencional que visa ao significado para dar sentidos à própria existência do ser. Por isso, compreendo que a mediação professor-aluno se faz na doação, doação de sentido, de intencionalidade.

Portanto, numa relação dialógica transdisciplinar e fundamentada, os conteúdos apresentados em aula ganham uma dimensão de importância, de significado rumo à uma aprendizagem emancipadora e humana, pois apreende o ato de conhecer numa dimensão fenomenológica/criativa; a consciência capta os fenômenos físicos, os naturais e os humanos de forma intencional e os compreende conforme a sua presença, relevância e importância para cada consciência, possibilitando novas reflexões e ampliando a consciência de mundo dos sujeitos envolvidos no processo de ensino-aprendizagem.

No ato educativo deve ser consideradas também as condições socioculturais, as diversidades econômicas, regionais, humanas, objetivas e subjetivas, as competências individuais dos grupos de trabalho em busca da autonomia dos sujeitos para se perceberem e se constituírem como pessoas, como cidadãos, como indivíduos que partilham o espaço social e que não estão sós. São sujeitos 
que fazem parte de um universo físico e humano complexo, movido por regras e normas oriundas da compreensão, do controle, da dominação e da consciência dos próprios homens, que necessitam se compreenderem como sujeitos, como seres de relações presentes no mundo. Por isso, acredito no trabalho pedagógico contextualizado nas situações de ensino-aprendizagem, conforme a compreensão e percepção do nível de conhecimento em que se encontram os educandos, todavia, de forma didático-pedagógica rigorosa como compreende a fenomenologia do a) o rigor acadêmico, para a construção da autonomia intelectual; b) o processo de afirmação da pessoa; c) a valorização do mundo vivido e das experiências do sujeito; d) a intencionalidade, o princípio de interação dialética sujeito/mundo; e) a relação professor-aluno, como espaço do diálogo para expressão da autonomia humana. Portanto, uma Escola Criativa torna-se espaço de humanização porque compreende e apreende o fenômeno educativo e atua como consciência de alguma coisa, consciência que visa algo, isto é, visa à educação. A Educação é um projeto humano, portanto dirige-se ao homem e sua humanização nas relações de ensinoaprendizagem buscando a autonomia do sujeito no ato de ensinar e aprender, tornando-o sujeito de sua aprendizagem.

\section{Referências}

BARRETO, José Carlos; BARRETO, Vera. Um sonho que não serve ao sonhador. In: . Construção coletiva: contribuições à educação de jovens e adultos. Brasilia: UNESCO; MEC; RAAAB, 2006.

BRASIL. Secretaria de Educação Fundamental. Parâmetros curriculares nacionais: introdução aos parâmetros curriculares nacionais / Secretaria de Educação Fundamental. - Brasilia: MEC/SEF, 1997.126p.

BICUDO, Maria Aparecida Viggiani; CAPELLETTI, Isabel Franchi (Orgs.).

Fenomenologia: uma visão abrangente da educação. São Paulo: Olho d’água, 1999.

CANDAU, Vera (org.) A didática em questão. Petrópolis: Rio de Janeiro, Vozes, 1995.

FREIRE, Paulo. Consciência e história: a práxis educativa de Paulo Freire (antologia). São Paulo: Loyola, 1978.

FREIRE, P. Pedagogia da autonomia: saberes necessários à prática educativa. Rio de Janeiro, Paz e Terra, 2004.

FREIRE, Paulo. Pedagogia do oprimido. 50.ed.rev, e atual. Rio de Janeiro: Paz e Terra, 2011.

HUSSERL, Edmund. A Crise da Humanidade Europeia e a Filosofia; introdução e tradução de Urbano Zilles. - 2a ed. Porto Alegre: EDIPUCRS, 2002 (Coleção filosofia vol. 41). 
PIMENTA, Selma. G.; ANASTASIOU, Léa das Graças Camargos. Docência no Ensino Superior. São Paulo: Cortez, 2002.

PIMENTA, Selma Garrido; LIMA, Maria Socorro Lucena. Estágio e docência: questões e propostas. 4. ed. São Paulo: Cortez, 2009.

SILVA, Carlos Cardoso. A Didática na Perspectiva Fenomenológica. Tese de Doutorado (Programa de Pós-Graduação em Educação) - Faculdade de Educação da Universidade Federal de Goiás, 2009. 275 p.

SEVERINO, Antônio Joaquim. A Contribuição da Filosofia para a Educação. Revista Em aberto, Brasília, ano 9, jan. mar, 1990.

SUANNO, Marilza Vanessa Rosa; SANTOS, Akiko; SUANNO, João Henrique. Didática e formação de professores: complexidade e transdisciplinaridade. Florianópolis: SC, 2013.

TORRE, S. de la. Dialogando con la creatividad. De la idendificación a la creatividad paradójica. Barcelona: Octaedro, 2003.

TORRE, S. de la. y VIOLANT, V. Creatividad aplicada. Barcelona: (2003), http:/ /

www.ub.edu/sentipensar/pdf/saturnino/nocion_creatividad.pdf em 20 de maio de 2017.

ZUBEN VON, Newton Aquiles. A Emergência do Sujeito e a Educação. In:

REZENDE, Antônio Muniz. Iniciação Teórica e Prática às Ciências da Educação.

Vozes: Petrópolis, RJ, 1979.

MANCUSO, R. y MORAES, R. Avaliação de mostras e feiras escolares: investigando as possibilidades de uma avaliação participativa dos trabalhos. Enseñanza de las Ciencias, Número Extra VIII Congreso Internacional sobre Investigación en Didáctica de las Ciencias, Barcelona, 2009, pp. 2091-2096. 